\title{
The impact of aerosol hygroscopic growth on the single-scattering albedo and its application on the $\mathrm{NO}_{2}$ photolysis rate coefficient
}

\author{
J. C. Tao ${ }^{1}$, C. S. Zhao ${ }^{1}$, N. Ma ${ }^{1,2}$, and P. F. Liu ${ }^{1,3}$ \\ ${ }^{1}$ Department of Atmospheric and Oceanic Sciences, School of Physics, Peking University, Beijing, China \\ ${ }^{2}$ Leibniz Institute for Tropospheric Research, Leipzig, Germany \\ ${ }^{3}$ School of Engineering and Applied Sciences, Harvard University, Cambridge, Massachusetts, USA
}

Correspondence to: C. S. Zhao (zcs@pku.edu.cn)

Received: 14 May 2014 - Published in Atmos. Chem. Phys. Discuss.: 20 June 2014

Revised: 19 September 2014 - Accepted: 4 October 2014 - Published: 17 November 2014

\begin{abstract}
Hygroscopic growth of aerosol particles can significantly affect their single-scattering albedo $(\omega)$, and consequently alters the aerosol effect on tropospheric photochemistry. In this study, the impact of aerosol hygroscopic growth on $\omega$ and its application to the $\mathrm{NO}_{2}$ photolysis rate coefficient $\left(J_{\mathrm{NO}_{2}}\right)$ are investigated for a typical aerosol particle population in the North China Plain (NCP). The variations of aerosol optical properties with relative humidity ( $\mathrm{RH})$ are calculated using a Mie theory aerosol optical model, on the basis of field measurements of number-size distribution and hygroscopic growth factor (at RH values above $90 \%$ ) from the 2009 HaChi (Haze in China) project. Results demonstrate that ambient $\omega$ has pronouncedly different diurnal patterns from $\omega$ measured at dry state, and is highly sensitive to the ambient RHs. Ambient $\omega$ in the NCP can be described by a dry state $\omega$ value of 0.863 , increasing with the RH following a characteristic RH dependence curve. A Monte Carlo simulation shows that the uncertainty of $\omega$ from the propagation of uncertainties in the input parameters decreases from 0.03 (at dry state) to 0.015 (RHs > $90 \%$ ). The impact of hygroscopic growth on $\omega$ is further applied in the calculation of the radiative transfer process. Hygroscopic growth of the studied aerosol particle population generally inhibits the photolysis of $\mathrm{NO}_{2}$ at the ground level, whereas accelerates it above the moist planetary boundary layer. Compared with dry state, the calculated $J_{\mathrm{NO}_{2}}$ at RH of $98 \%$ at the height of $1 \mathrm{~km}$ increases by $30.4 \%$, because of the enhancement of ultraviolet radiation by the humidified scattering-dominant aerosol particles. The increase of $J_{\mathrm{NO}_{2}}$ due to the aerosol hygroscopic growth above the upper boundary layer may affect the tropospheric photochemical processes and this needs to be taken into account in the atmospheric chemical models.
\end{abstract}

\section{Introduction}

Single-scattering albedo $(\omega)$ is one of the most important aerosol optical properties. It influences the aerosol's radiative effect and is a significantly uncertain factor. Defined as the ratio of absorption to the sum of scattering plus absorption, $\omega$ represents the combined effect of the two processes and acts as an indicator of aerosols' net radiative effect.

Under dry conditions ( $<30 \% \mathrm{RH})$, the value of $\omega$ is determined by the particle number-size distribution, the complex refractive index, and the particle shape (Covert et al., 1972). Due to the complexity of aerosol processes such as production, transformation, in situ chemical reactions, and removal, the value of $\omega$ is highly variable (Heintzenberg et al., 1997). Especially, aerosol scattering can be significantly enhanced by elevated relative humidity (RH). The hygroscopic growth of aerosol particles determines the water content in the particles and changes the composition and the size of aerosols. As a result, the value of $\omega$ varies with RH. In polluted areas, compared with dry state, scattering increases by at least $50 \%$ at RH of around $90 \%$, mainly from the increase of water (Cheng et al., 2008; Pan et al., 2009; Fierz-Schmidhauser et al., 2010b; Langridge et al., 2012; Li et al., 2013). This enhancement of scattering is stronger for marine aerosols or in clean regions (Fierz-Schmidhauser et al., 2010b; Carrico et al., 2000; Adam et al., 2012), and weaker for dust aerosol (Pan et al., 2009; Carrico et al., 2000). Aerosol absorption is often considered to vary slightly with $\mathrm{RH}$, while Brem et al. (2012) reported the enhancement of aerosol absorption at high RH. Thus, the value of $\omega$ can be RH dependent and increase by at least 0.05 at high RHs in a polluted atmosphere (Cheng et al., 2008; Fierz-Schmidhauser et al., 2010b; Li et 
al., 2013; Jung et al., 2009). Because ambient air is most often sampled in a shelter or structure, it is very important to measure and report the RH at the point of measurement and to apply coincident measurement of aerosol hygroscopicity (or a model thereof) to quantify the ambient $\omega$ (Nessler et al., 2005).

Due to the high sensitivity of radiative forcing to the variation of $\omega$, it is essential to obtain atmospherically relevant values of $\omega$ for climate models and photochemical models. It has long been known that the aerosol radiative forcing is sensitive to $\omega$, and the transition between positive and negative forcing of direct aerosol effect takes place when the value of $\omega$ is about 0.85 (Heintzenberg et al., 1997; Cheng et al., 2008; Wang et al., 2007). Combined with the other aerosol optical properties, the change of $\omega$ at high RHs can strengthen the forcing by a factor of 2 or more (Stock et al., 2011; FierzSchmidhauser et al., 2010a; Cheng et al., 2008; Massoli et al., 2009). As for the tropospheric photochemical process, $\omega$ as well as the aerosol optical depth $(\tau)$ are the relevant parameters in the determination of ultraviolet (UV) radiation and the photolysis rate coefficient (Reuder and Schwander, 1999). There are many important photolysis reactions in the troposphere, such as of $\mathrm{NO}_{2}$, ozone, etc. Among these reactions, the photolysis of $\mathrm{NO}_{2}$ accounts for the most ozone production in the troposphere and is the most representative. The $\mathrm{NO}_{2}$ photolysis rate coefficient $\left(J_{\mathrm{NO}_{2}}\right)$ is widely used in the analysis of ozone photochemistry (Seinfeld and Pandis, 2006; Dickerson et al., 1997; Palancar et al., 2013). Ozone photochemistry can be either inhibited or enhanced by aerosols also depending on $\omega$ (Palancar et al., 2013; Li et al., 2011; Dickerson et al., 1997; Tang et al., 2003; Liu et al., 2013). Sensitivity studies show that RH is as important as the aerosol loading in the influence of aerosol on ozone photolysis (He and Carmichael, 1999; Jacobson, 1998).

The North China Plain (NCP), with several megacities and as the location of many industries, suffers frequent severe aerosol pollution episodes (Xu et al., 2011; Ran et al., 2011, 2012; Liu et al., 2009). The rapid industrial development created numerous sources of primary aerosols and the precursors of secondary aerosol production. The intensive use of coal and biomass fuels makes the NCP a region of high concentration of black carbon. Clouds and precipitation in this region might be modified by high aerosol loading (Zhao et al., 2006; Deng et al., 2009). Strong absorption and core-shell mixing state of light-absorbing carbonaceous (LAC) were found (Ma et al., 2011, 2012). The growth factors at RHs of up to $98.5 \%$ measured by a high humidity tandem differential mobility analyzer (HH-TDMA) indicated the existence of a dominant more-hygroscopic group of aerosols (Liu et al., 2011). This result agreed well with the retrieved values from the microbalance UMT-2 (Mettler Toledo, Switzerland) (Liu et al., 2014) and in combination contributed to enhancing extinction at high RHs and to the low visibility on hazy days (Chen et al., 2012). Regional ozone pollution occurred in the $\mathrm{NCP}$, but the role of the radiation in ozone photochemistry at high aerosol conditions is still unresolved (Ran et al., 2011, 2012).

In this study, the RH dependence of aerosol optical properties are represented and their influences on UV radiation are investigated. A Mie code considering the coating of aerosols (Y. Cheng et al., 2009) and a radiation transfer model (Madronich and Flocke, 1997) are used. The descriptions of data, calculations and models are presented in Sect. 2; overviews of aerosol optical properties are in Sect. 3; results of modeled UVB irradiance and $J_{\mathrm{NO}_{2}}$ are represented in Sect. 4; and there is a summary in Sect. 5.

\section{Data and methodology}

\subsection{Measurements of the HaChi project}

\subsubsection{Sites description}

The HaChi (Haze in China) project was conducted in Wuqing $\left(39^{\circ} 23^{\prime} \mathrm{N}, 117^{\circ} 01^{\prime} \mathrm{E}\right)$ during the summer of 2009 and at the Tieta site $\left(39^{\circ} 06^{\prime} \mathrm{N}, 117^{\circ} 10^{\prime} \mathrm{E}\right)$ during the summer of 2010 , by the Peking University, China, and the Leibniz Institute for Tropospheric Research (TROPOS), Germany. Wuqing is surrounded by two megacities, i.e., Beijing and Tianjin, and is sensitive to the regional atmospheric pollution in the NCP. The Tieta site is located in an urban district, northwest of Tianjin City, surrounded by plenty of traffic, industries and buildings. Radiation and meteorological elements were measured during the campaign. The aerosol measurement at the Wuqing site is found to be representative of the NCP (Ma et al., 2011; Liu et al., 2011; Xu et al., 2011; Ran et al., 2011). So it is appropriate for the intercomparison between the two sites.

\subsubsection{Instruments}

Details of aerosol, radiation and meteorological parameters were investigated during the HaChi campaign. The measurements were performed in an aerosol sampling container that was maintained at a temperature of $22^{\circ} \mathrm{C}$. Ambient aerosols were sampled with a $\mathrm{PM}_{10}$ inlet $\left(16.67 \mathrm{~L} \mathrm{~min}^{-1}\right)$ installed on the top of a stainless steel tube with a diameter of $3 / 4 \mathrm{in}$. $(19 \mathrm{~mm})$ and $7 \mathrm{~m}$ above the ground level. The aerosol samples were dried by an automatic aerosol diffusion dryer to keep the sample RH at less than $30 \%$. Further information regarding aerosol measurements is documented in the relevant studies on aerosol in the HaChi project (Ma et al., 2011; Liu et al., 2009).

Particle number-size distribution (PNSD) in the range of $3 \mathrm{~nm}-10 \mu \mathrm{m}$ was determined by the combination of an aerodynamic particle sizer (APS Model 3321, TSI Inc., Shoreview, MN, USA) and a twin differential mobility particle sizer (TDMPS, TROPOS, Germany) with sampling frequency of $10 \mathrm{~min}$ operated at $\mathrm{RH}<30 \%$. The aerosol absorption coefficient at $637 \mathrm{~nm}$ was measured by a multiangle 
absorption photometer (MAAP Model 5012, Thermo, Inc., Waltham, MA, USA) with a temporal resolution of $1 \mathrm{~min}$ and could be transformed into mass concentration of lightabsorbing carbonaceous (LAC) with assumed mass absorption efficiency (MAE) of $6.6 \mathrm{~m}^{2} \mathrm{~g}^{-1}$. Particulate scattering coefficients at the wavelengths of 450,550 and $700 \mathrm{~nm}$ were measured by an integrating nephelometer (Model 3563, TSI Inc., Shoreview, MN, USA) every $1 \mathrm{~min}$. The geometric hygroscopic growth factor $\left(g\left(\mathrm{RH}, D_{\mathrm{p}}\right)\right)$ relative to the dry state was obtained from measurement of the HH-TDMA. The HHTDMA measured $g\left(\mathrm{RH}, D_{\mathrm{p}}\right)$ for particles in four selected increments (at 50,100, 200 and $250 \mathrm{~nm}$ ) at three RHs (90, 95 and $98.5 \%$ ) with an absolute accuracy of $\pm 1.2 \%$ for $98.5 \%$.

At the Tieta site, the CE-318 sun photometer was used to measure the aerosol optical depth at four wavelengths of 440, 670,870 and $1020 \mathrm{~nm}$. The UVB $(280-320 \mathrm{~nm})$ irradiance near the ground was measured using the ultraviolet pyranometer produced by Yankee Environmental Systems (YES Inc., USA). The pyranometer was cleaned every morning to avoid the influence of dust on the glass. Both data were averaged into hourly data during the daytime.

One-minute data of meteorological parameters, such as wind speed, wind direction, RH and temperature were observed by an automatic weather station (AWS) next to the aerosol-measurement containers. The data were averaged into 10 min averages in order to match the $10 \mathrm{~min}$ PNSD data.

\subsection{Methodology for $\omega$ calculation}

The RH dependence of $\omega$ and other aerosol optical parameters can be calculated using the averaged PNSD and the Mie code (BHCOAT; Y. F. Cheng et al., 2009), considering the aerosol hygroscopic growth and the mixing state. As in the work of Ma et al. (2012), a two-parameter aerosol model is used, in which aerosol components are divided into two classes: the LAC and less-absorbing components (inorganic salts and acids, and most of the organic compounds). The mixing state of the aerosol population is considered to be partially externally mixed (LAC only) and partially core-shell mixed (a LAC core coated by a less-absorbing component shell). When ambient RH gets higher, the shell can take up water. Both the diameter and the refractive index of the shell are modified. The diameters and the refractive indices of the externally mixed LAC and the core-shell mixed LAC are assumed to be constant at different RHs. PNSDs of the externally mixed LAC and core-shell mixed particles, and the diameters of the cores $\left(D_{\text {core }}\right)$ in different sizes of core-shell particles can be obtained from the parameter retrieved in the mixing state (Ma et al., 2012). Size-resolved hygroscopic growth factors are calculated from size-resolved hygroscopicity parameter $\kappa$ (Chen et al., 2012). Then the size-resolved refractive indices of the core-shell mixing particles needed in the Mie code are determined.

\subsubsection{Mixing state of LAC in the NCP}

Ma et al. (2012) proposed a new method to derive the mixing state of LAC and applied it in the NCP. As a simplified aerosol model (Wex et al., 2002; Cheng et al., 2006), aerosols' chemical components are divided into two classes based on their refractive indices, i.e., (1) the LAC and (2) the less-absorbing components. Within these classes, two types of particles are assumed: externally mixed LAC and coreshell LAC mixed with less-absorbing coating components. The mixing state of LAC for ambient aerosol is described by the ratio of the externally mixed LAC to the total mass of LAC:

$r_{\mathrm{ext}-\mathrm{LAC}}=\frac{M_{\mathrm{ext}-\mathrm{LAC}}}{M_{\mathrm{LAC}, \mathrm{obs}}}$,

where $M_{\text {ext-LAC }}$ is the mass of externally mixed LAC and $M_{\mathrm{LAC}, \text { obs }}$ is the total mass of LAC measured by MAAP. Details about the retrieval method and the mixing state of LAC in the NCP can be found in Ma et al. (2012).

\subsubsection{PNSDs of externally mixed LAC and core-shell mixed particles at dry state}

Under the assumption in Sect. 2.2.1, total PNSD of the aerosol population is comprised of subset PNSDs of the externally mixed LAC and the core-shell mixed particles, which are needed in the Mie calculation. At dry state, this relationship is described as

$N\left(\log D_{\mathrm{p}}\right)_{\text {measure }}=N\left(\log D_{\mathrm{p}}\right)_{\text {ext-LAC }}+N\left(\log D_{\mathrm{p}}\right)_{\text {core-shell }}$,

where $N\left(\log D_{\mathrm{p}}\right)_{\text {measure }}$ is the PNSD measured by TDMPS and APS for total aerosols, and $N\left(\log D_{\mathrm{p}}\right)_{\text {ext-LAC }}$ and $N\left(\log D_{\mathrm{p}}\right)_{\text {core-shell }}$ are the PNSDs of the externally mixed LAC and the core-shell mixed particles, respectively. $N\left(\log D_{\mathrm{p}}\right)_{\text {ext-LAC }}$ can be derived from the mixing state presented by Ma et al. (2012):

$N\left(\log D_{\mathrm{p}}\right)_{\text {ext-LAC }}=N\left(\log D_{\mathrm{p}}\right)_{\text {measure }} \cdot r_{\mathrm{ext}-\mathrm{LAC}} \cdot f_{\mathrm{LAC}}$,

where $f_{\text {LAC }}$ is the volume fraction of LAC, which can be calculated by

$f_{\mathrm{LAC}}=\frac{M_{\mathrm{LAC}, \text { obs }}}{\rho_{\mathrm{LAC}} \cdot \sum_{D_{\mathrm{p}}} N\left(\log D_{\mathrm{p}}\right)_{\text {measure }} \cdot\left(\frac{\pi}{6} \cdot D_{\mathrm{p}}^{3}\right)}$,

where $\rho_{\mathrm{LAC}}$ is the density of LAC, which is assumed to be $1.5 \mathrm{~g} \mathrm{~cm}^{-3}$ in this study.

\subsubsection{Size-resolved hygroscopic growth factors $\left(g\left(D_{\mathrm{p}}, \mathrm{RH}\right)\right)$}

The size-resolved hygroscopic growth factors at different RHs $\left(g\left(D_{\mathrm{p}}, \mathrm{RH}\right)\right)$ are calculated from the hygroscopic parameter $(\kappa)$ and are used in this study to obtain the ambient PNSD:

$g\left(D_{\mathrm{p}, \text { dry }}, \mathrm{RH}\right)=D_{\mathrm{p}}(\mathrm{RH}) / D_{\mathrm{p}, \mathrm{dry}}$, 
where $D_{\mathrm{p}}(\mathrm{RH})$ and $D_{\mathrm{p}, \text { dry }}$ are particle diameters at a specific $\mathrm{RH}$ and at dry state, respectively. While $g\left(D_{\mathrm{p}}, \mathrm{RH}\right)$ for the externally mixed LAC is assumed to be independent of RH and therefore does not grow at any RH.

As reported by Liu et al. (2011), two groups of particles can be distinguished based on their hygroscopicity, i.e., the nearly hydrophobic particles and the more-hygroscopic particles. Specifically, the nearly hydrophobic particles are composed mainly by the LAC and the primary organic aerosol (POA). In this study, the ambient aerosols are classified based on their mixing state, which is quite different from Liu et al. (2011). The core-shell mixed aerosol is composed of not only more-hygroscopic compositions, such as inorganic salts and acids, but also nearly hydrophobic compositions, such as POA and LAC. The hygroscopic behavior for the coreshell mixed aerosol cannot be represented definitively by Liu et al. (2011). However, as shown in the work of Liu et al. (2014), the less-absorbing component consists of the majority of the aerosol population (from 80 to $90 \%$ ) at all sizes. As a result, the size-resolved number fractions of the core-shell mixed aerosol are higher than $94 \%$, much larger than the externally mixed LAC, as is the hygroscopicity of the core-shell mixed aerosol. Therefore, the hygroscopicity of the core-shell mixed aerosol is much closer to that of the aerosol population. The ensemble mean $\kappa$ for all groups in Liu et al. (2011) can describe the hygroscopicity of the core-shell mixing particles and is used in the calculation of $g\left(D_{\mathrm{p}}, \mathrm{RH}\right)$.

As represented by the Köhler theory (Köhler, 1936; Petters and Kreidenweis, 2007), the relationship between $g$ and $\kappa$ at a specific temperature $(T)$ and $\mathrm{RH}$ is

$\mathrm{RH}=\frac{g^{3}-1}{g^{3}-(1-\kappa)} \cdot \exp \left(\frac{4 \sigma_{\mathrm{s} / \mathrm{a}} \cdot M_{\mathrm{water}}}{R \cdot T \cdot D_{\mathrm{p}} \cdot g \cdot \rho_{\mathrm{W}}}\right)$,

where $\sigma_{\mathrm{s} / \mathrm{a}}$ is the surface tension of the solution-air interface, $M_{\text {water }}$ is the molecular weight of water and $R$ is the universal gas constant. More information of the size-resolved $\kappa$ is shown in Chen et al. (2012). By solving Eq. (6), $g\left(\mathrm{RH}, D_{\mathrm{p}}\right)$ can be obtained for different RH and $D_{\mathrm{p}}$. The size of each bin for PNSD at ambient condition can be then calculated with Eq. (5).

\subsubsection{Size and $\mathrm{RH}$ dependence of refractive indices $\left(m\left(D_{\mathrm{p}}, \mathbf{R H}\right)\right)$}

In order to initialize the BHCOAT model, the diameter and the complex refractive indices of the core and the shell are needed. Considering the hydrophobic LAC, the diameter of the core is constant at all RHs, i.e.,

$D_{\text {core }}=D_{\mathrm{p}, \mathrm{dry}}\left(\frac{f_{\mathrm{LAC}}-f_{\mathrm{LAC}} \cdot r_{\mathrm{ext}-\mathrm{LAC}}}{1-f_{\mathrm{LAC}} \cdot r_{\mathrm{ext}-\mathrm{LAC}}}\right)^{\frac{1}{3}}$,

and the complex refractive index is set to be 1.96-0.66i (Seinfeld and Pandis, 2006). $r_{\text {ext-LAC }}$ is the ratio of the externally mixed LAC to the total mass of LAC, and $f_{\mathrm{LAC}}$ is the volume fraction of LAC, as defined in Eqs. (1) and (3), respectively.

At high RHs, the shell of aerosol takes up water and is dissolved, which means the complete internal mixture of water and less-absorbing components. Both the diameter (as shown in Eq. 5) and the refractive indices of the shell change at different RHs; i.e.,

$\widetilde{m}_{\text {shell }}=f_{\text {solute }} \cdot \widetilde{m}_{\text {solute }}+\left(1-f_{\text {solute }}\right) \cdot \widetilde{m}_{\text {water }}$,

where $f_{\text {solute }}$ is

$f_{\text {solute }}=\frac{D_{\mathrm{p} \text {,dry }}^{3}-D_{\text {core }}^{3}}{D_{\mathrm{p}}^{3}(\mathrm{RH})-D_{\text {core }}^{3}}$,

and $\widetilde{m}_{\text {shell }}, \widetilde{m}_{\text {solute }}, \widetilde{m}_{\text {water }}$ are the refractive indices of the shell, solute (i.e., $1.53-10^{-7} \mathrm{i}$; Wex et al., 2002) and water (i.e., $1.33-10^{-7} \mathrm{i}$; Seinfeld and Pandis, 2006).

For the accumulation mode, the volume fraction of the solute in the shell decreases to 40 and $20 \%$ at the RHs of 80 and $90 \%$ in the NCP. As a result, the refractive indices of the shell fall from $1.53-10^{-7} \mathrm{i}$ to $1.41-10^{-7} \mathrm{i}$ and $1.37-10^{-7} \mathrm{i}$, respectively. The volume fraction of solute is lower than $5 \%$ at $99 \% \mathrm{RH}$, resulting in a refractive index close to $1.33-10^{-7} \mathrm{i}$, i.e., the refractive indices of pure water, at $99 \% \mathrm{RH}$. Consequently, the consideration of $\mathrm{RH}$-dependent refractive indices is necessary for the calculation of $\omega$.

\subsubsection{Mie code}

The Mie code used in the study is an improvement from the BHCOAT code (Bohren and Huffman, 2008; Y. Cheng et al., 2009). In the Mie theory (Mie, 1908), the scattering efficiency $\left(Q_{\mathrm{sp}}\right)$ for a particle of a specific size can be calculated by integrating the intensity function $|S(\theta, x, m)|$ from 0 to $180^{\circ}$; i.e.,

$Q_{\mathrm{sp}}=\frac{1}{x^{2}} \int_{\theta}|S(\theta, x, m)| \sin (\theta) d \theta$,

where $x=\pi D_{\mathrm{p}} / \lambda . D_{\mathrm{p}}$ is the volume equivalent diameter of particles, $\lambda$ is the wavelength of radiation, and $\theta$ is the scattering angle.

Then the aerosol scattering coefficient $\left(\sigma_{\mathrm{sp}}\right)$ and aerosolabsorbing coefficient $\left(\sigma_{\mathrm{ap}}\right)$ are calculated as

$\sigma_{\mathrm{sp}}=\int_{D_{\mathrm{p}}} Q_{\mathrm{sp}} \cdot\left(\frac{\pi}{4} D_{\mathrm{p}}^{2}\right) \cdot N\left(\log D_{\mathrm{p}}\right) \cdot d \log D_{\mathrm{p}}$,
$\sigma_{\mathrm{ap}}=\int_{D_{\mathrm{p}}} \mathrm{Q}_{\mathrm{ap}} \cdot\left(\frac{\pi}{4} D_{\mathrm{p}}^{2}\right) \cdot N\left(\log D_{\mathrm{p}}\right) \cdot d \log D_{\mathrm{p}}$,

where $N\left(\log D_{\mathrm{p}}\right)$ is the PNSD. The $\sigma_{\mathrm{sp}}$ and $\sigma_{\text {ap }}$ of externally mixed LAC and core-shell mixed particles are individually calculated with Eqs. (11) and (12). And the overall $\sigma_{\mathrm{sp}}$ and $\sigma_{\text {ap }}$ of ambient aerosol can be obtained as the sum of those two classes. The aerosol extinction coefficient $\left(\sigma_{\mathrm{ep}}\right)$ is defined as $\sigma_{\mathrm{ep}}=\sigma_{\mathrm{sp}}+\sigma_{\mathrm{ap}}$, and $\omega$ is defined as $\omega=\sigma_{\mathrm{sp}} / \sigma_{\mathrm{ep}}$. 


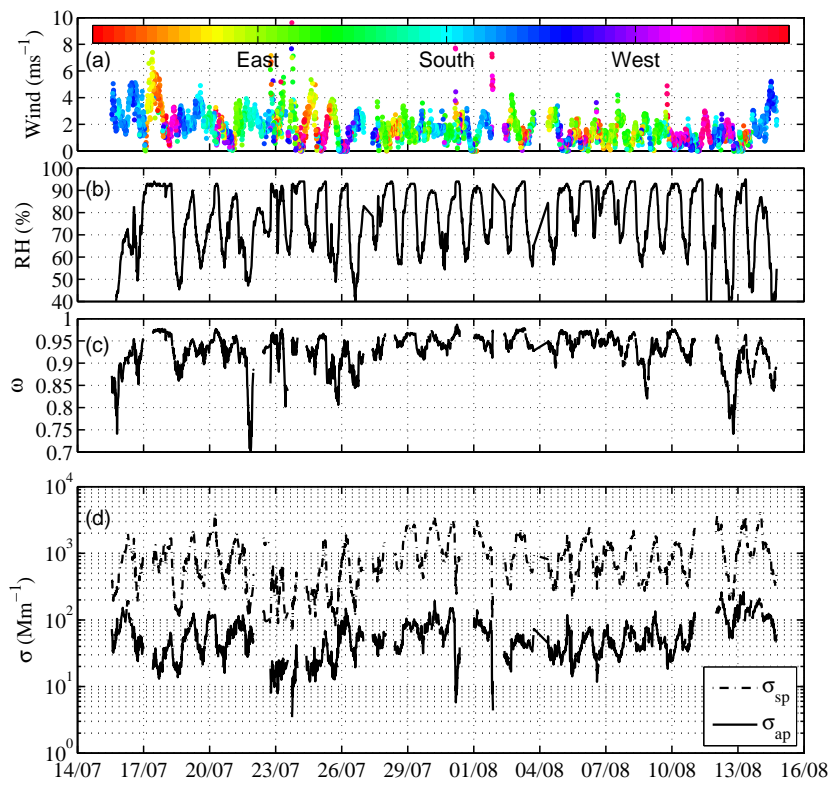

Figure 1. Time series of (a) wind speed and wind direction (denoted by the color of dots), (b) ambient RHs, (c) $\omega$, (d) $\sigma_{\mathrm{sp}}$ (dashed lines) and $\sigma_{\mathrm{sp}}$ (solid lines).

\subsection{The NCAR-TUV model}

The TUV (tropospheric ultraviolet and visible radiation, NCAR - National Center for Atmospheric Research) is an advanced radiative transfer model with an eight-stream, discrete ordinate solver (Madronich and Flocke, 1997). Given the information of aerosol and cloud optical properties, this model can calculate spectral irradiance over a wide range of wavelengths (from 121 to $\sim 735 \mathrm{~nm}$ ) and photolysis rate coefficients of important photochemical reactions in the atmosphere at a specific location and time. In this paper, irradiance at the wavelengths from 280 to $320 \mathrm{~nm}$ is calculated and compared with observations. $J_{\mathrm{NO}_{2}}$ is used to investigate the influence of aerosol on ozone photochemistry.

\section{Impact of hygroscopic growth on aerosol optical properties}

\subsection{Overview of the ambient aerosol optical properties}

Ambient aerosol optical characteristics, including $\sigma_{\mathrm{ep}}, \sigma_{\mathrm{sp}}$, $\sigma_{\mathrm{ap}}$ and $\omega$, are calculated using the method introduced in Sect. 2 for the data set measured during the HaChi summer campaign. The aerosol optical properties as well as the meteorological parameters during the observation period are shown in Fig. 1. For the majority of the observation, the 1 min wind speed is mostly less than $5 \mathrm{~m} \mathrm{~s}^{-1}$ (Fig. 1a) and the ambient RH is mostly between 60 and $95 \%$ (Fig. 1b). The overall $\sigma_{\mathrm{sp}}$ is within the range of $100-4000 \mathrm{Mm}^{-1}$, while the $\sigma_{\mathrm{ap}}$ is mainly lower than $200 \mathrm{Mm}^{-1}$ (Fig. 1d). As a result,

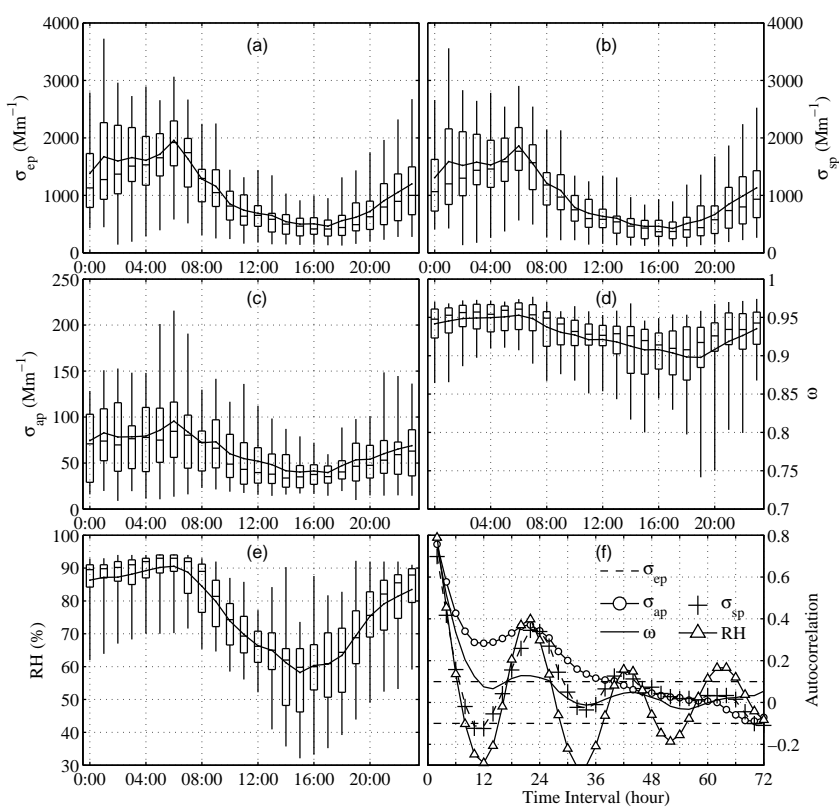

Figure 2. Average diurnal pattern of $\sigma_{\mathrm{ep}}(\mathbf{a}), \sigma_{\mathrm{sp}}(\mathbf{b}), \sigma_{\mathrm{ap}}(\mathbf{c}), \omega(\mathbf{d})$, ambient RHs (e) and the result of autocorrelation analysis of all the variables above (f) with the significant level of 0.1 (the dashed straight lines). The boxes and whiskers represent the 5, 25, 75, 95th percentiles.

the majority of $\omega$ is higher than 0.85 and is always close to 0.95 (Fig. 1c), which is in good agreement with the retrieved values from 0.85 to 0.95 by the Aerosol Robotic Network (AERONET) (Dubovik et al., 2002). The weakening effect of the wind on both $\sigma_{\mathrm{ap}}$ and $\sigma_{\mathrm{ap}}$ can be found, for example, on 25 July and 14 August. But at very high ambient RH, the decrease of $\sigma_{\mathrm{sp}}$ could be neutralized by the enhancement due to the hygroscopicity. As a consequence, the $\omega$ is affected pronouncedly by the RH and unaffected by the wind speed. From 17 to 18 July, when both the RH and the wind speed were high, $\omega$ approached the high value of 0.96 during the day, with relatively lower $\sigma_{\mathrm{ap}}$ compared with $\sigma_{\mathrm{sp}}$. By contrast, for example, on 16 and 22 July and 12 August, with typical wind speed (about $3 \mathrm{~m} \mathrm{~s}^{-1}$ ) and relatively low RH (about $50 \%$ ), the decrease of $\sigma_{\mathrm{sp}}$ was stronger than that of $\sigma_{\mathrm{ap}}$, and $\omega$ reached the low values of $0.75,0.7$ and 0.75 , respectively, on those three days. The value of $\omega$ was not sensitive to the direction of the wind. Significant diurnal patterns of $\omega$ can also be found and is confirmed as follows.

In Fig. 2, the diurnal variations of aerosol optical properties are analyzed and verified by calculating the autocorrelation coefficient. Pronounced diurnal patterns are found in all variables with a maximum at about 06:00 LT (local time) and a minimum at about 16:00 LT. Considering the 25 and 75th percentiles, values of $\sigma_{\mathrm{sp}}$ ranged from about 500 to about $2000 \mathrm{Mm}^{-1}$ (Fig. 2b), and $\sigma_{\text {ap }}$ ranged from about 40 to about $100 \mathrm{Mm}^{-1}$ (Fig. 2c). The ambient $\omega$ reached its maximum (about 0.95) at about 06:00 LT and minimum (about 


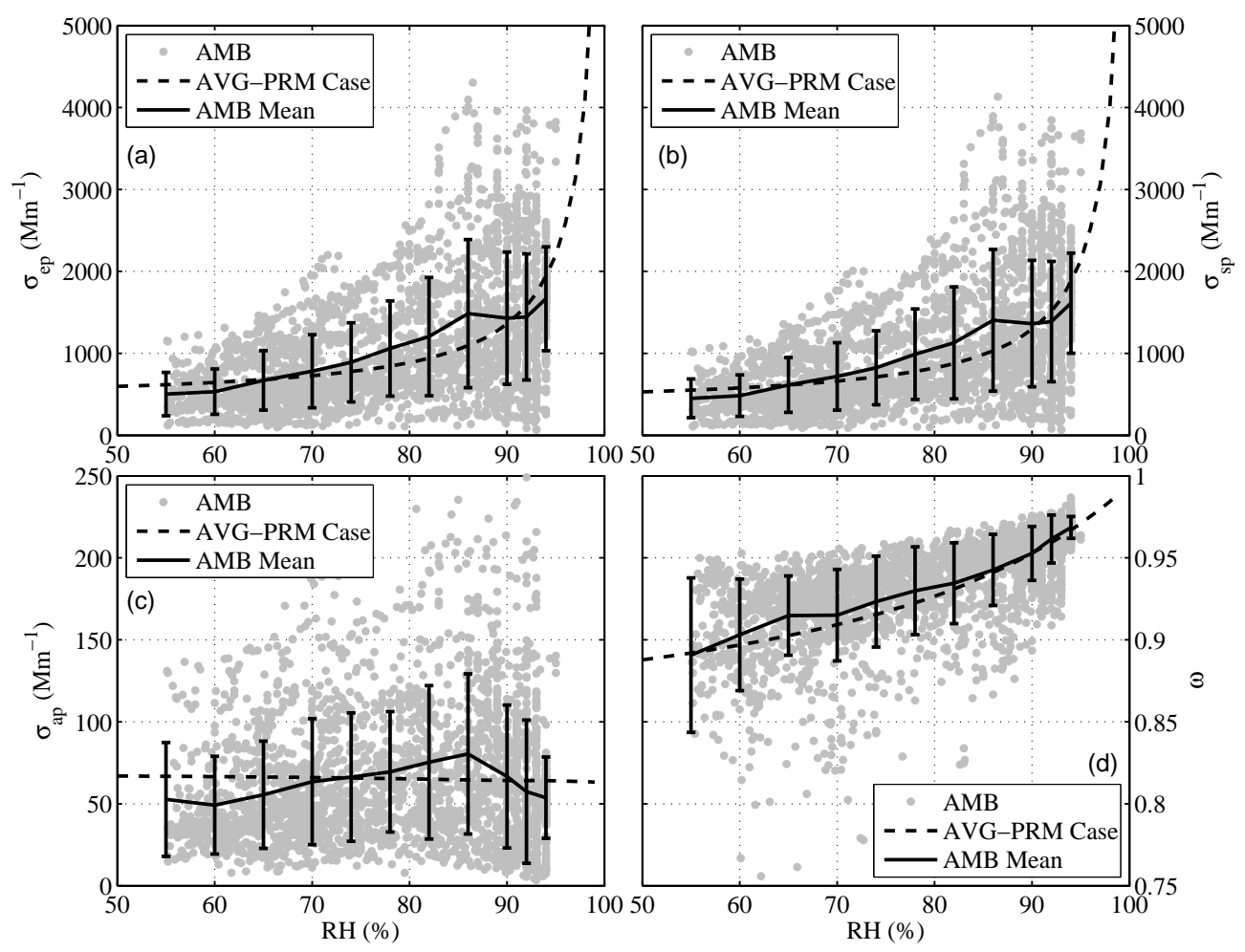

Figure 3. The dependence of $\sigma_{\mathrm{ep}}(\mathbf{a}), \sigma_{\mathrm{sp}}(\mathbf{b}), \sigma_{\mathrm{ap}}(\mathbf{c})$, and $\omega(\mathbf{d})$ at various RHs. The dots represent the ambient values of each measurement (AMB). The solid lines with bars represent the average and the deviation of the ambient values (AMB mean). The dashed lines represent the specific cases in which average input parameters are used (AVG-PRM case).

0.9) at about 18:00 LT (Fig. 2d), mainly attributed to the diurnal variation of ambient RH. These clear diurnal patterns are consistent with the high values (larger than 0.1 ) of the autocorrelation coefficient at the time intervals of $24 \mathrm{~h}$ (Fig. 2f). This obvious diurnal pattern of ambient $\omega$ may cause large variation of aerosol radiative forcing in climate models.

The diurnal patterns of the ambient $\sigma_{\mathrm{ep}}, \sigma_{\mathrm{sp}}$ and $\sigma_{\mathrm{ap}}$ are similar to their diurnal patterns in the dry state found by Ma et al. (2011). However, as Ma et al. (2011) reported, $\omega$ in the dry state reaches its peak at noon and a minimum in the morning and again in the evening, and the diurnal pattern of the $\omega$ is less notable. By taking aerosol hygroscopicity into account, the diurnal pattern of $\sigma_{\mathrm{sp}}$ is amplified because of the similar diurnal variation of ambient RH. However, the absorption is less influenced by the hygroscopic growth of particles. This large difference of amplification between $\sigma_{\mathrm{sp}}$ and $\sigma_{\mathrm{ap}}$ leads to the large modification of the diurnal pattern of ambient $\omega$ from that in dry state.

\subsection{The RH-dependent aerosol optical properties}

The aerosol optical properties are shown along with the ambient RHs in Fig. 3. The sensitivity of the $\sigma_{\mathrm{sp}}$ to the ambient $\mathrm{RH}$ is strong. The increases of $\sigma_{\mathrm{ep}}$ and $\sigma_{\mathrm{sp}}$ with the increase of RH are significant, although slight decreases occur at a $\mathrm{RH}$ of around $90 \%$ (Fig. 3a, b). So do the standard devia- tions (SD) of $\sigma_{\mathrm{ep}}$ and $\sigma_{\mathrm{sp}}$. However, $\sigma_{\mathrm{ap}}$ is not sensitive to $\mathrm{RH}$ and fluctuates slightly with the increase of RH (Fig. 3c). As a result, the enhancement of $\omega$ is sustained from about 0.89 at a RH of $55 \%$ to about 0.95 at a RH of $94 \%$ (Fig. 3d). More detailed statistical characteristics of these aerosol optical properties at different ranges of ambient RHs are listed in Table 1. It was found that the increase of the ambient $\omega$ from 0.87 to 0.96 brought about nearly 4.5 times the enhancement of aerosol direct radiative forcing (Cheng et al., 2008). In the $\mathrm{NCP}$, it is reasonable that the negative radiative forcing will be strengthened by the increase of $\omega$.

In addition, a specific case (the AVG-PRM case; dotted lines in Fig. 3) which used average parameters is calculated at different RHs. This case proves to be representative of the NCP by the analysis as follows, in Fig. 4, and is compared with the ambient aerosol optical properties here. The variations of the optical quantities in this case are smooth and monotonic. The congruence between the $\omega$ in the AVG-PRM case and the ambient mean $\omega$ is achieved, especially at high RHs. The AVG-PRM case is representative of the average status of the aerosol at various RHs in the NCP in summer and will be used in the following analysis of the $J_{\mathrm{NO}_{2}}$ profile.

The absorption coefficient of the aerosol in the NCP seems to be independent of RH in Fig. 3c, which is expected accord- 
Table 1. Statistical values of aerosol optical properties measured at different ranges of RH.

\begin{tabular}{llccccc}
\hline \multicolumn{2}{c}{$\mathrm{RH} /(\%)$} & $50 \sim 60$ & $60 \sim 70$ & $70 \sim 80$ & $80 \sim 90$ & $>90$ \\
\hline$\sigma_{\text {ep }}\left(\mathrm{Mm}^{-1}\right)$ & Mean & 478 & 654 & 953 & 1384 & 1479 \\
& SD & 252 & 363 & 535 & 839 & 746 \\
& Median & 415 & 558 & 771 & 1185 & 1349 \\
\hline \multirow{2}{*}{$\sigma_{\text {sp }}\left(\mathrm{Mm}^{-1}\right)$} & Mean & 429 & 599 & 885 & 1309 & 1421 \\
& Std & 230 & 335 & 503 & 802 & 715 \\
& Median & 371 & 515 & 729 & 1120 & 1305 \\
\hline \multirow{2}{*}{$\sigma_{a p}\left(\mathrm{Mm}^{-1}\right)$} & Mean & 50 & 56 & 68 & 75 & 58 \\
& Std & 30 & 34 & 39 & 48 & 40 \\
& Median & 38 & 46 & 60 & 65 & 49 \\
\hline \multirow{2}{*}{$\omega$} & Mean & 0.887 & 0.912 & 0.924 & 0.943 & 0.961 \\
& SD & 0.050 & 0.028 & 0.028 & 0.022 & 0.015 \\
& Median & 0.892 & 0.919 & 0.931 & 0.949 & 0.966 \\
\hline
\end{tabular}

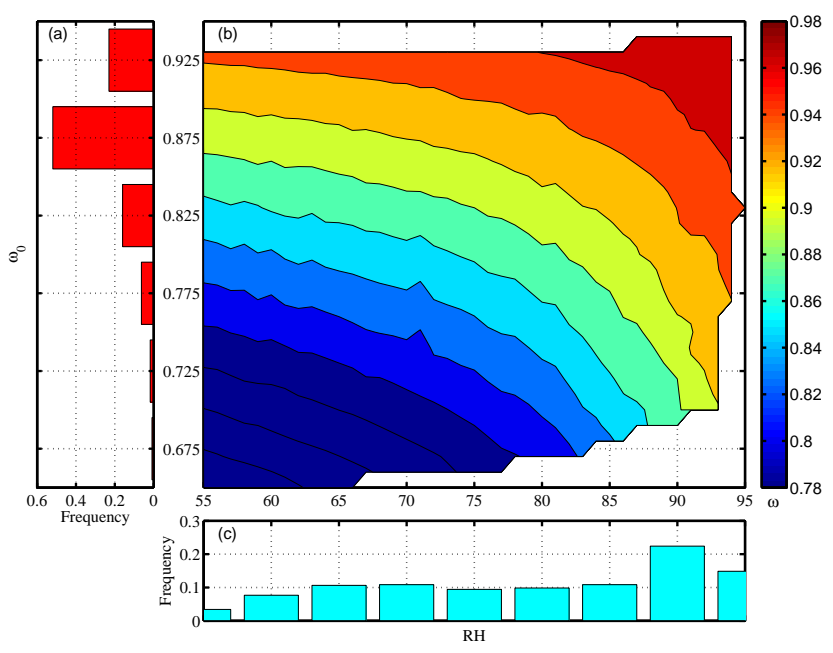

Figure 4. Frequency distributions of $\omega_{0}$ and RH (respectively, a and c). Calculated $\omega$ at given $\omega_{0}$ and $\mathrm{RH}(\mathbf{b})$.

ing to Pan et al (2009). Therefore, the value of $\omega$ at ambient conditions can be estimated from the two independent parameters: the ambient $\mathrm{RH}$ and $\omega$ at dry state $\left(\omega_{0}\right)$ (Pan et al., 2009). The relationship between $\omega$, RH and $\omega_{0}$ is presented in Fig. 4b, along with the frequency distribution of the measured $\omega_{0}$ (Fig. 4a) and RH (Fig. 4c). As expected, $\omega$ approaches higher values at either higher $\omega_{0}$ or higher $\mathrm{RH}$. Specifically, $\omega$ is more sensitive to $\omega_{0}$ at lower $\mathrm{RH}$ and more sensitive to $\mathrm{RH}$ at higher $\mathrm{RH}$.

The distribution of $\omega_{0}$ is mainly in the range of $0.80-0.95$ and has an average of about 0.86 (Fig. 4a), which agrees with the result in Ma et al. (2011). Considering that over half of the $\omega_{0}$ values are in the range of $0.85 \sim 0.9$, the value of 0.863 is representative for the NCP. The ambient RHs are distributed almost evenly between 60 and $95 \%$, except for the higher frequency at around $95 \%$ (Fig. 4c). It is essential to take the enhancement of $\omega$ at high RHs into account. To sum up, the majority of $\omega$ in the NCP can be described as the RH dependence at $\omega_{0}$ of 0.863 , i.e., $\omega\left(\omega_{0}=0.863, \mathrm{RH}\right)$, here referred to as the AVG-PRM case.

The overall influence of input parameters of the Mie model on $\omega$ at different RHs is investigated by a Monte Carlo simulation. As shown in Table 2, the uncertainties of both the measurements and the constants are assumed based on previous studies (Wiedensohler et al., 2012; Petzold and Schonlinner, 2004; Cheng et al., 2006). A detailed description can be found of Ma et al. (2012). The $\kappa_{i}$ in each mode and the

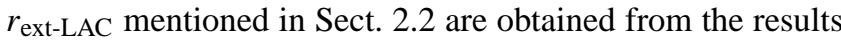
of relevant studies (Ma et al., 2012; Liu et al., 2011). Considering the wide range of the ambient RHs, the Monte Carlo simulations are conducted independently at different RHs. There are 2000 runs in each simulation and the standard deviations of $\omega$ reveal the uncertainty in the calculation of $\omega$.

The results of the Monte Carlo simulations are listed in Table 3. The standard deviation of $\omega$ is smaller at higher RH, ranging from 0.0308 at dry state to 0.0124 at the $\mathrm{RH}$ of $93 \%$. Moreover, we calculated $d \omega / d \mathrm{RH}$ and analyzed its influence on the standard deviation of $\omega . d \omega / d \mathrm{RH}$ is multiplied with the standard deviation of the RHs and then divides the standard deviation of the simulated $\omega$, i.e., $\left(\sigma_{\mathrm{RH}} \frac{d \omega}{d \mathrm{RH}}\right) / \sigma_{\omega}$. This variable represents the contribution of the uncertainty of measured RH on the uncertainty of calculated $\omega$. The results are characterized by the extremely low contribution $(<5 \%)$ at low RHs and the main contribution (> 50\%) at high RHs. These main contributions of the uncertainty of $\mathrm{RH}$ to the uncertainty of $\omega$ reflect the importance of the aerosol hygroscopic growth on the calculation of $\omega$ at high RHs. 
Table 2. Uncertainties of the input parameters in the Monte Carlo simulations.

\begin{tabular}{lc}
\hline Item & $\begin{array}{c}\text { Relative standard } \\
\text { deviation } \%\end{array}$ \\
\hline$D_{\mathrm{p}, \mathrm{TDMPS}}$ & 1.1 \\
$D_{\mathrm{p}, \mathrm{APS}}$ & 3 \\
$N_{\mathrm{TDMPS}, 3-20 \mathrm{~nm}}$ & 10 \\
$N_{\mathrm{TDMPS}, 20-200 \mathrm{~nm}}$ & 3.3 \\
$N_{\mathrm{TDMPS}, 200-700 \mathrm{~nm}}$ & 8.3 \\
$N_{\mathrm{APS}}$ & 3.3 \\
$\sigma_{\mathrm{ap}}$ & 4 \\
MAE $=6.6 \mathrm{~m}^{2} \mathrm{~g}^{-1}$ & 9.1 \\
$\rho_{\mathrm{LAC}}=1.5 \mathrm{~g} \mathrm{~cm}^{-3}$ & 11 \\
$n_{\mathrm{LAC}}=1.80$ & 0.5 \\
$i_{\mathrm{LAC}}=0.54$ & 0 \\
$n_{\text {non }}=1.55$ & 4 \\
$i_{\text {non }}=1 \mathrm{e}-7$ & 6.6 \\
$r_{\text {ext-LAC }}$ & 40 \\
$\kappa_{50 \mathrm{~nm}}=0.25$ & 24 \\
$\kappa_{100 \mathrm{~nm}}=0.27$ & 15 \\
$\kappa_{200 \mathrm{~nm}}=0.38$ & 13 \\
$\kappa_{250 \mathrm{~nm}}=0.39$ & 13 \\
$\mathrm{RH}$ & 3 \\
\hline
\end{tabular}

4 Impact of the aerosol hygroscopic growth on the $J_{\mathrm{NO}_{2}}$ profile: an application

\subsection{The relationship between the modeled UVB irradiance and $\omega$}

$J_{\mathrm{NO}_{2}}$ is affected pronouncedly by the UVB irradiance, which is determined by the solar zenith $(\theta), \omega$ and $\tau$. As shown in Fig. 5a, both the measured (dots) and the calculated (lines) UVB irradiance decreases with increasing (secant of) solar zenith angle $(\sec (\theta))$ and $\tau$. When $\omega$ is higher, UVB irradiance becomes larger. Clearer details are shown in Fig. 5b. The measured UVB at higher $\tau$ (the dots with warmer colors) is closer to the modeled UVB at higher $\omega$ (solid lines), while the measured UVB at lower $\tau$ (colder dots) is closer to the modeled UVB at lower $\omega$ (dashed lines). The relative deviations of UVB between the two $\omega$ conditions increase from about $10 \%(\tau=0.5)$ to about $700 \%(\tau=4.5)$. At higher $\tau$ (or RHs), the larger difference between high $\omega$ and low $\omega$ reveals the importance of an accurate value of $\omega$ for the UVB irradiance simulation. It is essential to take the aerosol hygroscopic growth into consideration in UVB simulations.

In order to understand the influence of RH-dependent $\omega$ on the UVB irradiation, the UVB irradiations both near the ground and above the boundary layer are calculated in three cases, i.e., the high- $\omega$ case, the low- $\omega$ case and the AVGPRM case. In the high- $\omega$ case and the low- $\omega$ case, UVB irradiations are calculated at a fixed $\omega$ with different $\tau$, similar to Dickerson et al (1997). In the AVG-PRM case, both $\tau$ and $\omega$ vary a lot with RHs, as presented in Table 4. As shown in
Table 3. The standard deviation of $\omega\left(\sigma_{\omega}\right)$, the rate of change of $\omega$ with RH $\left(\frac{d \omega}{d \mathrm{RH}}\right)$ and the contribution of RH to the uncertainty of $\omega\left(\sigma_{\mathrm{RH}} \frac{d \omega}{d \mathrm{RH}} / \sigma_{\omega}\right)$ at different RHs.

\begin{tabular}{cllc}
\hline $\mathrm{RH}(\%)$ & $\sigma_{\omega}$ & $\frac{d \omega}{d \mathrm{RH}}$ & $\left(\sigma_{\mathrm{RH}} \frac{d \omega}{d \mathrm{RH}}\right) / \sigma_{\omega}(\%)$ \\
\hline 0 & 0.0308 & 0.024 & 2.3 \\
10 & 0.0285 & 0.034 & 3.5 \\
20 & 0.0289 & 0.057 & 5.9 \\
30 & 0.0282 & 0.058 & 6.1 \\
40 & 0.0260 & 0.065 & 7.51 \\
50 & 0.0247 & 0.092 & 11.2 \\
60 & 0.0227 & 0.114 & 15.1 \\
70 & 0.0200 & 0.155 & 23.2 \\
80 & 0.0174 & 0.192 & 33.0 \\
82 & 0.0159 & 0.240 & 45.3 \\
84 & 0.0154 & 0.240 & 46.8 \\
86 & 0.0144 & 0.260 & 54.2 \\
88 & 0.0136 & 0.285 & 62.9 \\
90 & 0.0133 & 0.313 & 70.7 \\
91 & 0.0128 & 0.320 & 75.0 \\
92 & 0.0127 & 0.320 & 75.6 \\
93 & 0.0124 & 0.325 & 78.6 \\
\hline
\end{tabular}

Fig. 6, the UVB irradiation in all cases near the ground (the solid lines) decrease as $\tau$ rises. The decrease of the low- $\omega$ case is stronger than that of the high- $\omega$ case. For the AVGPRM case, a transformation of the UVB irradiation from the low- $\omega$ case to high- $\omega$ case can be recognized. Specifically, when $\tau$ is about 1.6, $\omega$ is higher than 0.96 and the closer value to the high- $\omega$ case is expected. Considering this stronger increase of $\omega$ than $\tau$ at RHs lower than $90 \%$, the transformation mentioned above is rapid. At the top of the boundary layer (dashed lines), as $\tau$ increases, the UVB irradiations in the low- $\omega$ case decrease while the UVB irradiations in the high- $\omega$ case decrease slowly only at high $\tau$. Similarly to the result at the surface, UVB irradiation in the AVG-PRM case gets closer to the high- $\omega$ case quickly as $\tau$ increases and stays undiminished until $\tau$ becomes higher than 2.5. In the polluted NCP in moist summers, both the aerosol loading and the ambient RHs are always high, resulting in both high $\tau$ and high $\omega$. High UVB irradiance is likely to happen at high $\tau$ and will affect relevant radiative processes, such as the photolysis of ozone and $\mathrm{NO}_{2}$.

\subsection{The influence of aerosol hygroscopic growth on the $\mathrm{JNO}_{2}$ profile}

In Fig. 7a and b, we represent the modeled $J_{\mathrm{NO}_{2}}$ at different conditions to study the influence of RH-dependent $\omega$ on photolysis. The $\omega$ values are 0.863 (lowest value in the NCP) and 0.985 (highest value in the NCP). For the $J_{\mathrm{NO}_{2}}$ profile at $\tau$ of 0 (or the original profile), the surface $J_{\mathrm{NO}_{2}}$ is about $0.011 \mathrm{~s}^{-1}$, and the maximum of $J_{\mathrm{NO}_{2}}$ is at the higher level, 

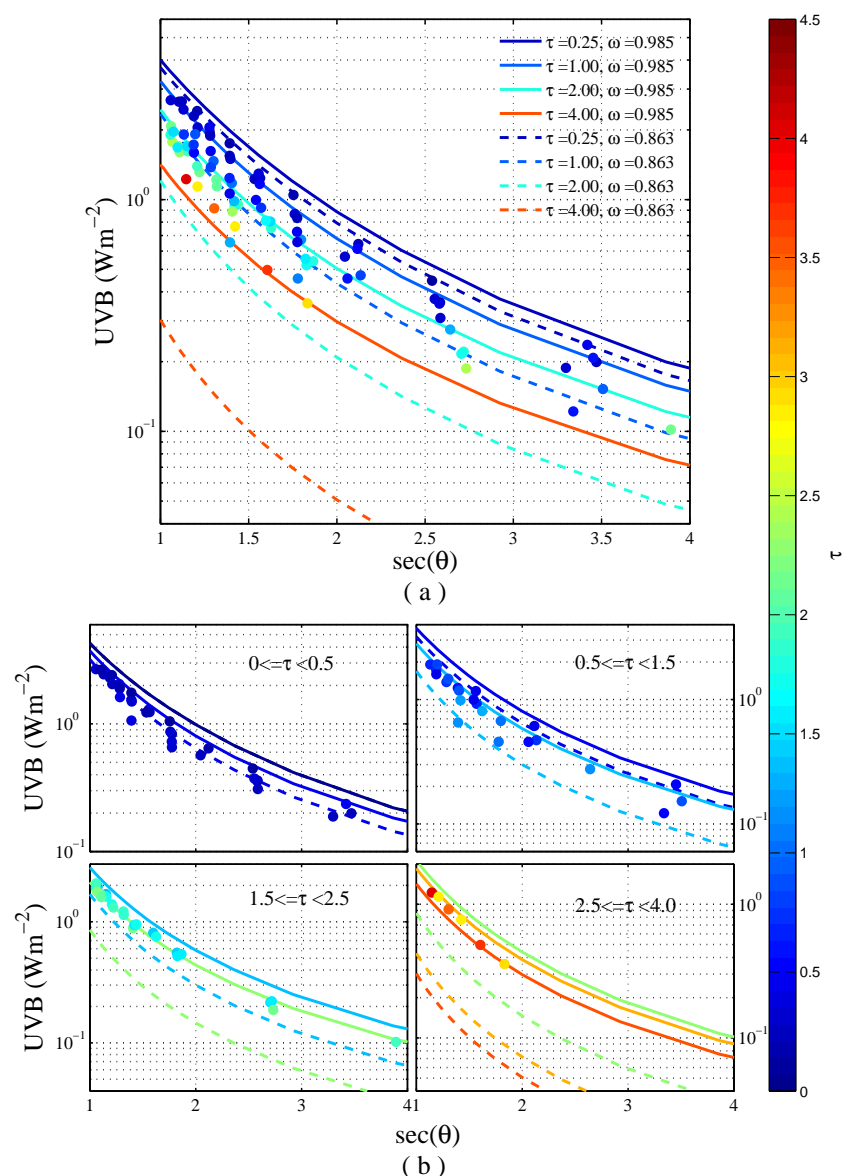

Figure 5. (a) The dots represent the measured UVB irradiance. The lines represents the modeled UVB irradiance at $\omega$ of 0.863 (dashed lines) and 0.985 (solid lines). Colors represent the value of $\tau$, i.e., the warmer/colder the color is, the higher/lower $\tau$ is revealed. (b) Identical to (a) but with finer ranges of $\tau$ as shown in the figures.

with its value of about $0.014 \mathrm{~s}^{-1}$. As $\tau$ increases, $J_{\mathrm{NO}_{2}}$ decreases the most in the low- $\omega$ case, especially in the range of $2 \mathrm{~km}$ above the ground (Fig. 7a). For the high- $\omega$ case, $J_{\mathrm{NO}_{2}}$ decreases near the ground but increases at heights higher than $2 \mathrm{~km}$. At the height of $2 \mathrm{~km}, J_{\mathrm{NO}_{2}}$ at $\tau$ of 4.5 is about $0.019 \mathrm{~s}^{-1}$, enhanced by about $58.3 \%$ compared with $J_{\mathrm{NO}_{2}}$ at $\tau$ of 0 (Fig. 7b). At heights lower than $2 \mathrm{~km}$ and above the surface, $J_{\mathrm{NO}_{2}}$ increases first and decreases later. At $1 \mathrm{~km}$ above the ground, $J_{\mathrm{NO}_{2}}$ increases by $39 \%$ and then decreases by $6 \%$. These results are in accordance with the study of Dickerson et al. (1997).

In Fig. 7c, the vertical profiles of $J_{\mathrm{NO}_{2}}$ at different $\tau$ values are calculated with the AVG-PRM case. Similarly to the high- $\tau$ case, $J_{\mathrm{NO}_{2}}$ at high altitudes become larger at higher $\tau$. At the height of $1 \mathrm{~km}, J_{\mathrm{NO}_{2}}$ increases by $58.3 \%$ at $\tau$ of 4.16, which is larger than in the high- $\omega$ case. At heights lower than $2 \mathrm{~km}$ and above the surface, the decreases of $J_{\mathrm{NO}_{2}}$ start at lower altitudes and are smaller than in the high- $\omega$ case.
Table 4. The values of $\tau$ and $\omega$ at selected RHs from the AVG-PRM case.

\begin{tabular}{ccc}
\hline $\mathrm{RH} / \%$ & $\tau$ & $\omega$ \\
\hline 0 & 0.51 & 0.863 \\
15 & 0.53 & 0.872 \\
30 & 0.55 & 0.878 \\
45 & 0.59 & 0.887 \\
55 & 0.64 & 0.895 \\
64 & 0.69 & 0.904 \\
73 & 0.79 & 0.916 \\
86 & 1.12 & 0.942 \\
90 & 1.39 & 0.954 \\
92 & 1.61 & 0.961 \\
94 & 1.99 & 0.968 \\
95 & 2.24 & 0.972 \\
96 & 2.64 & 0.976 \\
97 & 3.19 & 0.980 \\
98 & 4.16 & 0.985 \\
\hline
\end{tabular}

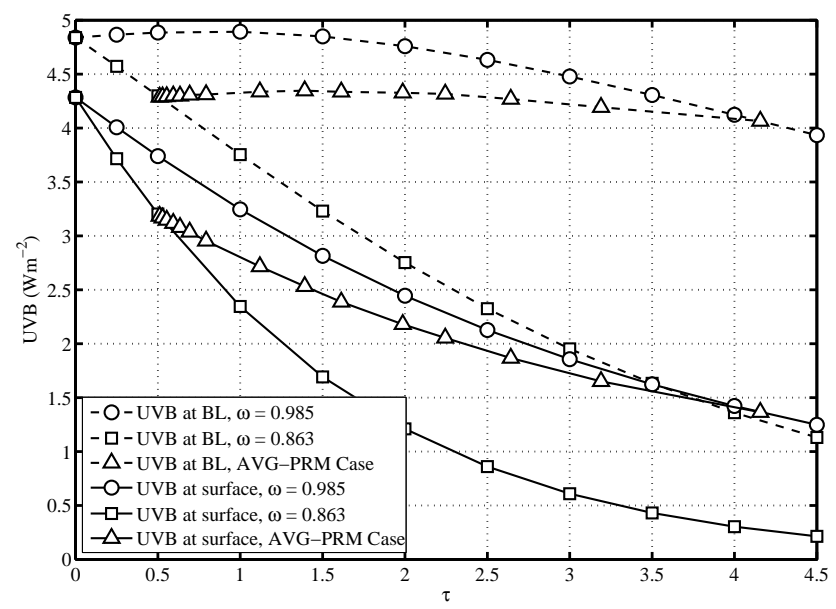

Figure 6. The dependence of UVB irradiance with $\tau$ at the surface (solid lines) and at the top of the boundary layer (dashed lines) in three cases: $\omega=0.985$ (circle), $\omega=0.863$ (square) and RHdependent $\omega$ (AVG-PRM case; triangle).

And at the height of $1 \mathrm{~km}, J_{\mathrm{NO}_{2}}$ increases by $30.4 \%$ at $\tau$ of 4.16. This feature may lead to a higher $J_{\mathrm{NO}_{2}}$ at the top of the boundary layer in the AVG-PRM case.

$d J_{\mathrm{NO}_{2}} / d \tau$ at the height of $1 \mathrm{~km}$ for different $\tau$ values are shown in Fig. 8. In the low- $\omega$ case, the negative $d J_{\mathrm{NO}_{2}} / d \tau$ is maintained and reaches its minimum when $\tau$ is between 2 and 2.5. In the high- $\omega$ case, the growth rate is positive when $\tau$ is lower than 2.5 and becomes negative when $\tau$ is higher than 3, resulting in a maximum of $J_{\mathrm{NO}_{2}}$ when $\tau$ is between 2.5 and 3 . In the AVG-PRM case, $d J_{\mathrm{NO}_{2}} / d \tau$ is positive when $\tau$ is lower than 4 and is likely to stay positive as $\tau$ increases. Compared with the high- $\omega$ case, $d J_{\mathrm{NO}_{2}} / d \tau$ in the AVG-PRM case is higher and stays positive, resulting in higher $J_{\mathrm{NO}_{2}}$ at higher $\tau$ conditions. This higher increase of 


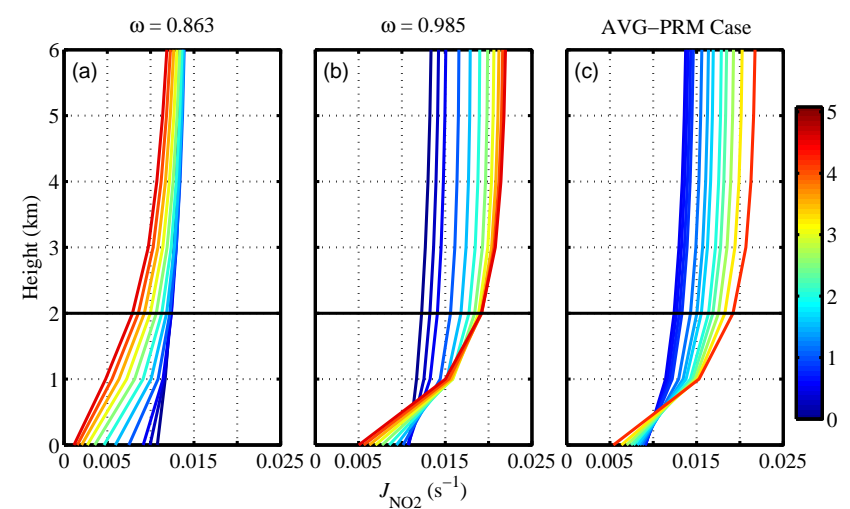

Figure 7. Altitude profiles of $J_{\mathrm{NO}_{2}}$ in three cases (a, b, c), as in Fig. 6. Colors represent the value of $\tau$, as expected. The black lines indicate the height of $2 \mathrm{~km}$.

$J_{\mathrm{NO}_{2}}$ may result in a weaker decrease of ozone photolysis in polluted conditions and the heavy ozone pollution may take place along with high $\tau$ in the moist and polluted NCP.

\section{Summary}

In this paper, the aerosol optical properties at different RHs, including $\sigma_{\mathrm{ep}}, \sigma_{\mathrm{sp}}, \sigma_{\mathrm{ap}}$ and $\omega$, are calculated with a Mie model based on the aerosol measurements during the HaChi project. The impact of the aerosol hygroscopic growth from HH-TDMA on $\omega$ and the corresponding uncertainty are analyzed. A derived parameter, the influence of $\mathrm{RH}$-dependent $\omega$ on the UVB irradiance and the $J_{\mathrm{NO}_{2}}$ are also investigated.

The hygroscopic growth influences not only aerosol PNSDs but also the refractive index of the aerosol. In this study, the shell of the core-shell mixed aerosol is assumed to be composed of less-absorbing, water-soluble components with the refractive index of $1.53-10^{-7} \mathrm{i}$. As the ambient RH increases, water vapor is taken up by the shell and the lessabsorbing components dissolve to maintain water vapor equilibrium between the ambient air and the liquid shell. The refractive index of the shell is determined by the water content and the solute together, and decreases with the RH. At the RH of $90 \%$, the refractive index of the shell of the accumulationmode aerosol decreases to $1.37-10^{-7} \mathrm{i}$, which is close to the refractive index of water. The variations of the refractive indices and PNSDs with RH will modify the aerosol optical properties by Mie theory.

Ambient aerosol optical characteristics, such as $\sigma_{\mathrm{ep}}, \sigma_{\mathrm{sp}}$, $\sigma_{\mathrm{ap}}$ and $\omega$, during the HaChi summer campaign are calculated. A significant sensitivity of $\omega$ to the ambient RH is recognized, which is mainly attributed to the variations of refractive indices and the aerosol size due to hygroscopic growth. Because of the sensitivity to the $\mathrm{RH}$, the diurnal patterns of $\sigma_{\mathrm{ep}}$ and $\sigma_{\mathrm{sp}}$ are evident and similar to the diurnal pattern of ambient RH. Compared with the diurnal patterns at dry state in Ma et al. (2011), the variations of the ambi-

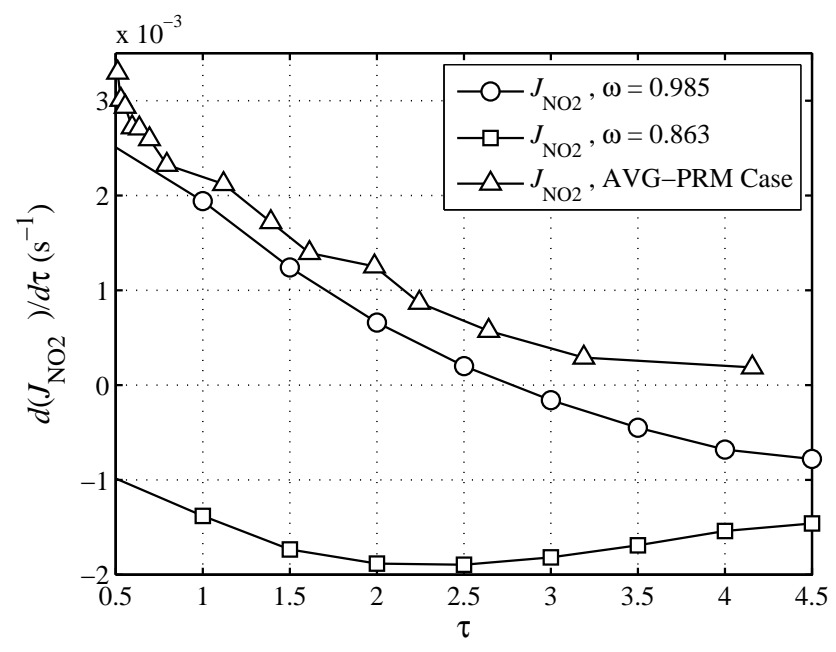

Figure 8. The increase of $J_{\mathrm{NO}_{2}}$ with $\tau$ for three cases: $\omega=0.985$ (circle), $\omega=0.863$ (square) and an RH-dependent $\omega$ (AVG-PRM case; triangle).

ent $\sigma_{\mathrm{ep}}$ and the ambient $\sigma_{\mathrm{sp}}$ are amplified pronouncedly. The diurnal variation of the ambient $\sigma_{\mathrm{ap}}$ is gentle and similar to that at dry state in Ma et al. (2011). Due to the strong enhancement of $\sigma_{\mathrm{sp}}$ and the slight increase of $\sigma_{\mathrm{ap}}$ with $\mathrm{RH}$, the diurnal pattern of $\omega$ is significant and changes a lot compared with that at dry state reported by Ma et al. (2011). Considering the insensitivity of $\sigma_{\text {ap }}$ to $\mathrm{RH}$, the ambient $\omega$ can be determined by its value at dry state, i.e., $\omega_{0}$, and RH. By analyzing its frequency, $\omega_{0}$ during the HaChi campaign concentrated mostly at the value of 0.863 . Therefore, the RH dependence of $\omega$ in the NCP can be represented by a dry state $\omega$ of 0.863 , increasing with the RH following a characteristic RH dependence curve (the AVG-PRM case). This representative RH-dependent $\omega$ can be used in the calculation of the radiative transfer process. The uncertainty of the calculation of $\omega$ due to the uncertainty of the input parameters in the Mie model is also investigated by Monte Carlo simulations. The result shows that the standard deviation of $\omega$ decreases from 0.03 at lower RHs to 0.013 at RHs higher than $90 \%$.

The RH-dependent $\omega$ is applied in the analysis of the $J_{\mathrm{NO}_{2}}$ (the photolysis rate coefficient of $\mathrm{NO}_{2}$, whose photolysis accounts for the most tropospheric ozone production) profile to evaluate the impact of aerosol hygroscopic growth on ozone photochemistry. $J_{\mathrm{NO}_{2}}$ depends on the UV irradiances and is thus affected by aerosol optical properties. The influence of $\omega$ on the UVB irradiances is investigated by comparing the modeled UVB irradiances and measured UVB irradiances. A good agreement between the model result and the observation is reached. It is demonstrated that the modeled UVB irradiances are sensitive to $\omega$, especially at high $\tau$, indicating the importance of the accuracy of $\omega$ in the calculation of UVB irradiances. Then the UVB irradiation at the RHdependent $\omega$ condition (the AVG-PRM case) is analyzed. The variations of the UVB irradiation with $\tau$ at the RH-dependent 
$\omega$ are close to those at a fixed high $\omega$. This similarity between the RH-dependent $\omega$ case and fixed high- $\omega$ case results from the stronger enhancement of $\omega$ than $\tau$ at RHs lower than $90 \%$, and is important in the study of $J_{\mathrm{NO}_{2}}$. Previous studies show that at a fixed high $\omega, J_{\mathrm{NO}_{2}}$ at the top of the boundary layer increases with $\tau$. This amplification of $J_{\mathrm{NO}_{2}}$ can weaken the inhibition of the aerosol on ozone photolysis and may bring about simultaneous high aerosol loading and high ozone concentration. In this study, $J_{\mathrm{NO}_{2}}$ at the RH-dependent $\omega$ is found to increase with $\tau$ as well. At $\tau$ of $4.16, J_{\mathrm{NO}_{2}}$ at the height of $1 \mathrm{~km}$ increases by $30.4 \%$ compared with that at $\tau$ of 0.51 . The weakening of suppression of ozone production by aerosol is likely to happen in the polluted and moist NCP, and may lead to more ozone production in polluted conditions. The increase of $J_{\mathrm{NO}_{2}}$ due to the aerosol hygroscopic growth above the upper boundary layer may affect the ozone photochemistry and this should be introduced and evaluated in the atmospheric chemical models.

Acknowledgements. This work is supported by the National 973 project of China (2011CB403402), the National Natural Science Foundation of China (41375134) and the Beijing Natural Science Foundation (8131003).

Edited by: D. Covert

\section{References}

Adam, M., Putaud, J. P., Martins dos Santos, S., Dell'Acqua, A., and Gruening, C.: Aerosol hygroscopicity at a regional background site (Ispra) in Northern Italy, Atmos. Chem. Phys., 12, 5703-5717, doi:10.5194/acp-12-5703-2012, 2012.

Bohren, C. F., Huffman, D. R.: Absorption and Scattering of Light by Small Particles, John Wiley, Hoboken, NJ, USA, 477-482, 1983.

Brem, B. T., Mena Gonzalez, F. C., Meyers, S. R., Bond, T. C., and Rood, M. J.: Laboratory-measured optical properties of inorganic and organic aerosols at relative humidities up to $95 \%$, Aerosol Sci. Technol., 46, 178-190, 2012.

Carrico, C. M., Rood, M. J., Ogren, J. A., Neususs, C., Wiedensohler, A., and Heintzenberg, J.: Aerosol optical properties at Sagres, Portugal during ACE-2, Tellus B - Chem. Phys. Meteorol., 52, 694-715, doi:10.1034/j.1600-0889.2000.00049.x, 2000.

Chen, J., Zhao, C. S., Ma, N., Liu, P. F., Göbel, T., Hallbauer, E., Deng, Z. Z., Ran, L., Xu, W. Y., Liang, Z., Liu, H. J., Yan, P., Zhou, X. J., and Wiedensohler, A.: A parameterization of low visibilities for hazy days in the North China Plain, Atmos. Chem. Phys., 12, 4935-4950, doi:10.5194/acp-12-4935-2012, 2012.

Cheng, Y., Wiedensohler, A., Eichler, H., Heintzenberg, J., Tesche, M., Ansmann, A., Wendisch, M., Su, H., Althausen, D., and Herrmann, H.: Relative humidity dependence of aerosol optical properties and direct radiative forcing in the surface boundary layer at Xinken in Pearl River Delta of China: An observation based numerical study, Atmos. Environ., 42, 6373-6397, 2008.

Cheng, Y., Berghof, M., Garland, R., Wiedensohler, A., Wehner, B., Müller, T., Su, H., Zhang, Y., Achtert, P., and Nowak, A.: Influence of soot mixing state on aerosol light absorption and single scattering albedo during air mass aging at a polluted regional site in northeastern China, J. Geophys. Res. Atmos., 114, D00G10, doi:10.1029/2008JD010883, 2009.

Cheng, Y. F., Eichler, H., Wiedensohler, A., Heintzenberg, J., Zhang, Y. H., Hu, M., Herrmann, H., Zeng, L. M., Liu, S., Gnauk, T., Bruggemann, E., and He, L. Y.: Mixing state of elemental carbon and non-light-absorbing aerosol components derived from in situ particle optical properties at Xinken in Pearl River Delta of China, J. Geophys. Res.-Atmos., 111, D20204, doi:10.1029/2005JD006929, 2006.

Cheng, Y. F., Berghof, M., Garland, R. M., Wiedensohler, A., Wehner, B., Muller, T., Su, H., Zhang, Y. H., Achtert, P., Nowak, A., Poschl, U., Zhu, T., Hu, M., and Zeng, L. M.: Influence of soot mixing state on aerosol light absorption and single scattering albedo during air mass aging at a polluted regional site in northeastern China, J. Geophys. Res.-Atmos., 114, D00G10, doi:10.1029/2008JD010883, 2009.

Covert, D. S., Charlson, R., and Ahlquist, N.: A study of the relationship of chemical composition and humidity to light scattering by aerosols, J. Appl. Meteorol., 11, 968-976, 1972.

Deng, Z., Zhao, C., Zhang, Q., Huang, M., and Ma, X.: Statistical analysis of microphysical properties and the parameterization of effective radius of warm clouds in Beijing area, Atmos. Res., 93, 888-896, doi:10.1016/j.atmosres.2009.04.011, 2009.

Dickerson, R. R., Kondragunta, S., Stenchikov, G., Civerolo, K. L., Doddridge, B. G., and Holben, B. N.: The impact of aerosols on solar ultraviolet radiation and photochemical smog, Science, 278, 827-830, doi:10.1126/science.278.5339.827, 1997.

Dubovik, O., Holben, B., Eck, T. F., Smirnov, A., Kaufman, Y. J., King, M. D., Tanré, D., and Slutsker, I.: Variability of absorption and optical properties of key aerosol types observed in worldwide locations, J. Atmos. Sci., 59, 590-608, 2002.

Fierz-Schmidhauser, R., Zieger, P., Gysel, M., Kammermann, L., DeCarlo, P. F., Baltensperger, U., and Weingartner, E.: Measured and predicted aerosol light scattering enhancement factors at the high alpine site Jungfraujoch, Atmos. Chem. Phys., 10, 2319-2333, doi:10.5194/acp-10-2319-2010, 2010a.

Fierz-Schmidhauser, R., Zieger, P., Vaishya, A., Monahan, C., Bialek, J., O’Dowd, C. D., Jennings, S. G., Baltensperger, U., and Weingartner, E.: Light scattering enhancement factors in the marine boundary layer (Mace Head, Ireland), J. Geophys. Res.Atmos., 115, D20204, doi:10.1029/2009jd013755, 2010b.

He, S. and Carmichael, G. R.: Sensitivity of photolysis rates and ozone production in the troposphere to aerosol properties, J. Geophys. Res.-Atmos., 104, 26307-26324, doi:10.1029/1999jd900789, 1999.

Heintzenberg, J., Charlson, R. J., Clarke, A. D., Liousse, C., Ramaswamy, V., Shine, K. P., Wendisch, M., and Helas, G.: Measurements and modelling of aerosol single-scattering albedo: progress, problems and prospects, Contrib. Atmos. Phys., 70, 249-263, 1997.

Jacobson, M. Z.: Studying the effects of aerosols on vertical photolysis rate coefficient and temperature profiles over an urban airshed, J. Geophys. Res.-Atmos., 103, 10593-10604, doi:10.1029/98jd00287, 1998.

Jung, J., Lee, H., Kim, Y. J., Liu, X. G., Zhang, Y. H., Gu, J. W., and Fan, S. J.: Aerosol chemistry and the effect of aerosol water content on visibility impairment and radiative forcing in Guangzhou 
during the 2006 Pearl River Delta campaign, J. Environ. Manage., 90, 3231-3244, doi:10.1016/j.jenvman.2009.04.021, 2009.

Köhler, H.: The nucleus in and the growth of hygroscopic droplets, Trans. Faraday Soc., 32, 1152-1161, 1936.

Langridge, J. M., Lack, D., Brock, C. A., Bahreini, R., Middlebrook, A. M., Neuman, J. A., Nowak, J. B., Perring, A. E., Schwarz, J. P., Spackman, J. R., Holloway, J. S., Pollack, I. B., Ryerson, T. B., Roberts, J. M., Warneke, C., de Gouw, J. A., Trainer, M. K., and Murphy, D. M.: Evolution of aerosol properties impacting visibility and direct climate forcing in an ammonia-rich urban environment, J. Geophys. Res.-Atmos., 117, D00V11, doi:10.1029/2011jd017116, 2012.

Li, C., Tsay, S. C., Hsu, N. C., Kim, J. Y., Howell, S. G., Huebert, B. J., Ji, Q., Jeong, M. J., Wang, S. H., Hansell, R. A., and Bell, S. W.: Characteristics and composition of atmospheric aerosols in Phimai, central Thailand during BASE-ASIA, Atmos. Environ., 78, 60-71, doi:10.1016/j.atmosenv.2012.04.003, 2013.

Li, G., Bei, N., Tie, X., and Molina, L. T.: Aerosol effects on the photochemistry in Mexico City during MCMA2006/MILAGRO campaign, Atmos. Chem. Phys., 11, 5169-5182, doi:10.5194/acp-11-5169-2011, 2011.

Liu, H. J., Zhao, C. S., Nekat, B., Ma, N., Wiedensohler, A., van Pinxteren, D., Spindler, G., Müller, K., and Herrmann, H.: Aerosol hygroscopicity derived from size-segregated chemical composition and its parameterization in the North China Plain, Atmos. Chem. Phys., 14, 2525-2539, doi:10.5194/acp-14-25252014, 2014.

Liu, P., Zhao, C., Zhang, Q., Deng, Z., Huang, M., Ma, X., and Tie, X.: Aircraft study of aerosol vertical distributions over Beijing and their optical properties, Tellus B, 61, 756-767, 2009.

Liu, P., Zhang, Y., and Martin, S. T.: Complex Refractive Indices of Thin Films of Secondary Organic Materials by Spectroscopic Ellipsometry from 220 to $1200 \mathrm{~nm}$, Environ. Sci. Technol., 47, 13594-13601, 2013.

Liu, P. F., Zhao, C. S., Göbel, T., Hallbauer, E., Nowak, A., Ran, L., Xu, W. Y., Deng, Z. Z., Ma, N., Mildenberger, K., Henning, S., Stratmann, F., and Wiedensohler, A.: Hygroscopic properties of aerosol particles at high relative humidity and their diurnal variations in the North China Plain, Atmos. Chem. Phys., 11, 3479-3494, doi:10.5194/acp-11-3479-2011, 2011.

Ma, N., Zhao, C. S., Nowak, A., Müller, T., Pfeifer, S., Cheng, Y. F., Deng, Z.Z., Liu, P. F., Xu, W. Y., Ran, L., Yan, P., Göbel, T., Hallbauer, E., Mildenberger, K., Henning, S., Yu, J., Chen, L. L., Zhou, X. J., Stratmann, F., and Wiedensohler, A.: Aerosol optical properties in the North China Plain during HaChi campaign: an in-situ optical closure study, Atmos. Chem. Phys., 11, 5959-5973, doi:10.5194/acp-11-5959-2011, 2011.

Ma, N., Zhao, C. S., Müller, T., Cheng, Y. F., Liu, P. F., Deng, Z. Z., Xu, W. Y., Ran, L., Nekat, B., van Pinxteren, D., Gnauk, T., Müller, K., Herrmann, H., Yan, P., Zhou, X. J., and Wiedensohler, A.: A new method to determine the mixing state of light absorbing carbonaceous using the measured aerosol optical properties and number size distributions, Atmos. Chem. Phys., 12, 2381-2397, doi:10.5194/acp-12-2381-2012, 2012.

Madronich, S. and Flocke, S.: Theoretical estimation of biologically effective UV radiation at the Earth's surface, NATO ASI series I, Global Environ. Change, 52, 23-48, 1997.

Massoli, P., Bates, T. S., Quinn, P. K., Lack, D. A., Baynard, T., Lerner, B. M., Tucker, S. C., Brioude, J., Stohl, A., and
Williams, E. J.: Aerosol optical and hygroscopic properties during TexAQS-GoMACCS 2006 and their impact on aerosol direct radiative forcing, J. Geophys. Res.-Atmos., 114, D00F07, doi:10.1029/2008jd011604, 2009.

Mie, G.: Beiträge zur Optik trüber Medien, speziell kolloidaler Metallösungen, Annalen der Physik, 330, 377-445, 1908.

Nessler, R., Weingartner, E., and Baltensperger, U.: Adaptation of dry nephelometer measurements to ambient conditions at the Jungfraujoch, Environ. Sci. Technol., 39, 2219-2228, 2005.

Palancar, G. G., Lefer, B. L., Hall, S. R., Shaw, W. J., Corr, C. A., Herndon, S. C., Slusser, J. R., and Madronich, S.: Effect of aerosols and NO2 concentration on ultraviolet actinic flux near Mexico City during MILAGRO: measurements and model calculations, Atmos. Chem. Phys., 13, 1011-1022, doi:10.5194/acp13-1011-2013, 2013.

Pan, X. L., Yan, P., Tang, J., Ma, J. Z., Wang, Z. F., Gbaguidi, A., and Sun, Y. L.: Observational study of influence of aerosol hygroscopic growth on scattering coefficient over rural area near Beijing mega-city, Atmos. Chem. Phys., 9, 7519-7530, doi:10.5194/acp-9-7519-2009, 2009.

Petters, M. D. and Kreidenweis, S. M.: A single parameter representation of hygroscopic growth and cloud condensation nucleus activity, Atmos. Chem. Phys., 7, 1961-1971, doi:10.5194/acp-71961-2007, 2007.

Petzold, A. and Schonlinner, M.: Multi-angle absorption photometry - a new method for the measurement of aerosol light absorption and atmospheric black carbon, J. Aerosol Sci., 35, 421-441, doi:10.1016/j.jaerosci.2003.09.005, 2004.

Ran, L., Zhao, C. S., Xu, W. Y., Lu, X. Q., Han, M., Lin, W. L., Yan, P., Xu, X. B., Deng, Z. Z., Ma, N., Liu, P. F., Yu, J., Liang, W. D., and Chen, L. L.: VOC reactivity and its effect on ozone production during the HaChi summer campaign, Atmos. Chem. Phys., 11, 4657-4667, doi:10.5194/acp-11-4657-2011, 2011.

Ran, L., Zhao, C. S., Xu, W. Y., Han, M., Lu, X. Q., Han, S. Q., Lin, W. L., Xu, X. B., Gao, W., Yu, Q., Geng, F. H., Ma, N., Deng, Z. Z., and Chen, J.: Ozone production in summer in the megacities of Tianjin and Shanghai, China: a comparative study, Atmos. Chem. Phys., 12, 7531-7542, doi:10.5194/acp-12-75312012, 2012.

Reuder, J. and Schwander, H.: Aerosol effects on UV radiation in nonurban regions, J. Geophys. Res.-Atmos., 104, 4065-4077, doi:10.1029/1998jd200072, 1999.

Seinfeld, J. H. and Pandis, S. N.: Atmospheric chemistry and physics: from air pollution to climate change, Wiley, Inc., New York, USA, 701-1118, 2006.

Stock, M., Cheng, Y. F., Birmili, W., Massling, A., Wehner, B., Muller, T., Leinert, S., Kalivitis, N., Mihalopoulos, N., and Wiedensohler, A.: Hygroscopic properties of atmospheric aerosol particles over the Eastern Mediterranean: implications for regional direct radiative forcing under clean and polluted conditions, Atmos. Chem. Phys., 11, 4251-4271, doi:10.5194/acp11-4251-2011, 2011.

Tang, Y. H., Carmichael, G. R., Uno, I., Woo, J. H., Kurata, G., Lefer, B., Shetter, R. E., Huang, H., Anderson, B. E., Avery, M. A., Clarke, A. D., and Blake, D. R.: Impacts of aerosols and clouds on photolysis frequencies and photochemistry during TRACE-P: 2. Three-dimensional study using a regional chemical transport model, J. Geophys. Res.-Atmos., 108, 8822, doi:10.1029/2002JD003100, 2003. 
Wang, W., Rood, M. J., Carrico, C. M., Covert, D. S., Quinn, P. K., and Bates, T. S.: Aerosol optical properties along the northeast coast of North America during the New England Air Quality Study - Intercontinental Transport and Chemical Transformation 2004 campaign and the influence of aerosol composition, J. Geophys. Res.-Atmos., 112, D10S23, doi:10.1029/2006JD007579, 2007.

Wex, H., Neusüß, C., Wendisch, M., Stratmann, F., Koziar, C., Keil, A., Wiedensohler, A., and Ebert, M.: Particle scattering, backscattering, and absorption coefficients: An in situ closure and sensitivity study, J. Geophys. Res. Atmos., 107, LAC 41-LAC 4-18, 2002.

Wiedensohler, A., Birmili, W., Nowak, A., Sonntag, A., Weinhold, K., Merkel, M., Wehner, B., Tuch, T., Pfeifer, S., Fiebig, M., Fjaraa, A. M., Asmi, E., Sellegri, K., Depuy, R., Venzac, H., Villani, P., Laj, P., Aalto, P., Ogren, J. A., Swietlicki, E., Williams, P., Roldin, P., Quincey, P., Huglin, C., Fierz-Schmidhauser, R., Gysel, M., Weingartner, E., Riccobono, F., Santos, S., Gruning, C., Faloon, K., Beddows, D., Harrison, R. M., Monahan, C., Jennings, S. G., O’Dowd, C. D., Marinoni, A., Horn, H. G., Keck, L., Jiang, J., Scheckman, J., McMurry, P. H., Deng, Z., Zhao, C. S., Moerman, M., Henzing, B., de Leeuw, G., Loschau, G., and Bastian, S.: Mobility particle size spectrometers: harmonization of technical standards and data structure to facilitate high quality long-term observations of atmospheric particle number size distributions, Atmospheric Measurement Techniques, 5, 657-685, doi:10.5194/amt-5-657-2012, 2012.
Xu, W. Y., Zhao, C. S., Ran, L., Deng, Z. Z., Liu, P. F., Ma, N., Lin, W. L., Xu, X. B., Yan, P., He, X., Yu, J., Liang, W. D., and Chen, L. L.: Characteristics of pollutants and their correlation to meteorological conditions at a suburban site in the North China Plain, Atmos. Chem. Phys., 11, 4353-4369, doi:10.5194/acp-114353-2011, 2011.

Zhao, C. S., Tie, X. X., and Lin, Y. P.: A possible positive feedback of reduction of precipitation and increase in aerosols over eastern central China, Geophys. Res. Lett., 33, L11814, doi:10.1029/2006g1025959, 2006. 